\title{
Microwave-assisted Synthesis of ZnO Nanoparticles Stabilized with Gum Arabic: Effect of Microwave Irradiation Time on ZnO Nanoparticles Size and Morphology
}

\author{
Norlin Pauzi, Norashikin Mat Zain*, Nurul Amira Ahmad Yusof \\ Faculty Chemical and Natural Resources Engineering, University Malaysia Pahang, \\ Lebuhraya Tun Razak, 26300 Gambang, Kuantan, Pahang, Malaysia
}

Received: 1 ${ }^{\text {st }}$ October 2018; Revised: $22^{\text {nd }}$ November 2018; Accepted: $12^{\text {nd }}$ December 2018; Available online: 25th January 2019; Published regularly: April 2019

\begin{abstract}
The conventional heating methods of nanoparticle synthesis regularly depend on the energy inputs from outer heat sources that resulted high energy intake and low reaction competences. In this paper $\mathrm{ZnO}$ nanoparticles stabilized with gum arabic are synthesized using precipitating method assisted by simple and cost effective microwave heating technique. The objective of this work is to investigate the effect of microwave irradiation time towards $\mathrm{ZnO}$ nanoparticles morphology and size. The effect of microwave irradiation time has been investigated at 2, 4, 6, and 10 minutes. Dynamic Light Scattering (DLS) was employed to measure the size of $\mathrm{ZnO}$ nanoparticles. Ultraviolet-Visible spectroscopy (UVvis), Fourier-Transform Infrared Spectroscopy (FTIR) and X-Ray Diffraction (XRD) were used for the characterization of the $\mathrm{ZnO}$ nanoparticles. UV-vis absorption spectrum was found in the range of 350 $\mathrm{nm}$ indicating the absorption peak of $\mathrm{ZnO}$ nanoparticles. FTIR spectra showed peaks range from 424 to $475 \mathrm{~cm}^{-1}$ which indicating standard of $\mathrm{Zn}-\mathrm{O}$ stretching. The presence of (100), (002), and (101) planes were apparent in the XRD result, indicating the crystalline phase of $\mathrm{ZnO}$ nanoparticles. The increase in the microwave irradiation time affected the processes of nucleation and crystal growth promoted larger $\mathrm{ZnO}$ nanoparticles size. Microwave irradiation time at 2 minutes was selected as the best microwave irradiation time for smallest $\mathrm{ZnO}$ nanoparticles averaging about $168 \mathrm{~nm}$ sizes based on DLS analysis. Copyright (C) 2019 BCREC Group. All rights reserved
\end{abstract}

Keywords: Microwave Heating; Irradiation Time; ZnO Nanoparticle; Gum Arabic

How to Cite: Pauzi, N., Zain, N.M., Yusof, N.A.A. (2019). Microwave-assisted Synthesis of ZnO Nanoparticles Stabilized with Gum Arabic: Effect of Microwave Irradiation Time on ZnO Nanoparticles Size and Morphology. Bulletin of Chemical Reaction Engineering \& Catalysis, 14 (1): 182-188 (doi:10.9767/bcrec.14.1.3320.182-188)

Permalink/DOI: https://doi.org/10.9767/bcrec.14.1.3320.182-188

\section{Introduction}

Zinc oxide $(\mathrm{ZnO})$ is a promising wide band gap semiconductor $\left(E_{g}=3.37 \mathrm{eV}\right)$ and with a

* Corresponding Author.

E-mail: shikin@ump.edu.my (N.M. Zain)

Telp: +6017-328 1653 binding energy of $60 \mathrm{meV}$ [1]. It has several favorable properties such as having a good thermal and mechanical stability, biodegradability, strong room temperature luminescence and antibacterial properties. $\mathrm{ZnO}$ nanoparticles are popular among scientists worldwide as they have unique chemical, physical and biological 
properties for wide industrial application. However, for industrial synthesis of $\mathrm{ZnO}$ nanoparticles repeatable properties faced difficult and troublesome issues. Normally the challenges are difficult to control the average particle size, particle size distribution, shape as well as phase purity.

There are several methods for the synthesis of $\mathrm{ZnO}$ nanoparticles including precipitation in solution [2], spray pyrolysis [3], hydrothermal synthesis [4], and sol-gel processes [5]. Hydrothermal growth methods are frequently correlated with long growth times, normally $10 \mathrm{~h}$ or greater using conventional hot-plate methods $[7,8]$. Microwave heating is able to reduce the growth length to minutes while maintaining good morphology and $\mathrm{ZnO}$ crystallinity. Publications on microwave-assisted synthesis as chemically green synthesis of chemical product has increased in order to eliminate the generation of hazardous substances and to reduce intensive energy consumption [8,9]. Several issued of different experimental variables over $\mathrm{ZnO}$ nanoparticles size, morphology, and physicochemical performances have been studied [10]. Microwave offers an adaptable heating mode to control the synthesis of nanoparticles. The wavelength of microwave has a strong effect on the penetration depths in the reaction solution, and thus can speed up the heating rate [11]. Consequently, the nucleation and the growth of nanoparticles are controllable [12]. Besides that, this method shows narrow particle size distribution, high purity materials and improved physicochemical properties [13].

In this present paper, $\mathrm{ZnO}$ nanoparticles stabilized with gum arabic were synthesized by using a microwave-assisted method. The current work emphasized on the green synthesis of $\mathrm{ZnO}$ nanoparticles using gum arabic (stabilizing agent). This stabilizing agent is a complex polysaccharide, which is extracted from the stems and branches of acacia trees [14]. Gum arabic is a hydrophilic, biocompatible, non-toxic and ecofriendly polymer [15]. When the gum arabic is adsorbed on the particle surface, steric hindrance, bridging or charge-patch are formed to stabilize the particles [16]. To the author's best knowledge, there appear to be no published studies on the microwave-assisted synthesis of $\mathrm{ZnO}$ nanoparticles using gum arabic as stabilizing agent.

Different microwave irradiation times will synthesize different $\mathrm{ZnO}$ nanoparticles size and morphology [17]. Several studies had revealed the morphology changes with microwave irradiation time forming different types of complex nanostructures [15,16]. Although the synthesis process using stabilizing agent such as (sodium di-2-ethylhexyl-sulfosuccinate (AOT), it was difficult to control the growth under longer microwave irradiation time. In this present paper, research was conducted to investigate the effect of microwave irradiation time towards $\mathrm{ZnO}$ nanoparticles morphology and size using gum arabic as a stabilizing agent.

Previously, the size of $\mathrm{ZnO}$ nanoparticles was characterized using FESEM, TEM, and XRD [2,3]. Nevertheless, DLS was preferable in the current study as larger number of particles (in millions) could be measured via DLS [21]. The error in the size determination by dynamic light scattering method for spherical particles is rather low, not greater than $5-10 \%$ [22]. Therefore, in this study the more reliable size distribution can be obtained by using DLS.

\section{Materials and Methods}

\subsection{Materials}

Both zinc nitrate hexahydrate $\mathrm{Zn}\left(\mathrm{NO}_{3}\right)_{2}$. $6 \mathrm{H}_{2} \mathrm{O}(98 \%$, Aldrich) and sodium hydroxide $(98.9 \%$, Bendosen) of analytical grade were used without further chemical treatment and purification. The zinc salt used in this study was zinc nitrate so that the very pure phase of $\mathrm{ZnO}$ nanoparticles of high density could be obtained using microwave heating method [18]. Gum arabic was purchased from Texture Innovation Centre (TIC Gums), USA. Gum arabic solution was used straightaway after dissolving it in the de-ionized water in order to obtain reproducible results. De-ionized water was ob-

Table 1. PDI for $\mathrm{ZnO}$ nanoparticles synthesis at 2 min of microwave irradiation time

\begin{tabular}{ccccccc}
\hline $\begin{array}{c}\text { Z-Average } \\
(\mathrm{nm})\end{array}$ & PDI & PDI Width & $\begin{array}{c}\text { Percent in } \\
\text { Size Range }\end{array}$ & $\mathrm{D}(10)$ & $\mathrm{D}(50)$ & $\mathrm{D}(80)$ \\
\hline 168 & 0.101 & 54.21 & 100 & 116 & 180 & 283 \\
\hline
\end{tabular}

PDI=Polydispersity index

$\mathrm{D}=$ particle size distributions in $10 \%, 50 \%$ and $80 \%$ 
tained from the Laboratory of Faculty of Chemical and Natural Resources Engineering, University Malaysia Pahang.

\subsection{Method of ZnO Nanoparticles Synthesis}

Firstly, 1\% of gum arabic was dissolved in $100 \mathrm{~mL}$ of distilled water and heated at 350 Watt to dissolve the gum arabic. Amount of $2.974 \mathrm{~g}$ of solid $\mathrm{Zn}\left(\mathrm{NO}_{3}\right)_{2} .6 \mathrm{H}_{2} \mathrm{O}$ zinc nitrate was added into $1 \%$ of gum arabic solution subjected to continuous stirring. Then the obtained solution was heated for 2 minutes in the microwave running at $350 \mathrm{~W}$ to fully dissolve the Zinc nitrate and gum arabic. $1 \mathrm{M} \mathrm{NaOH}$ solution was dripped into the zinc nitrate and gum arabic solution undergoing vigorous stirring until $\mathrm{pH} 10$ achieved. Again, the mixture solution was exposed to microwave heating 350 watt at 2 min-
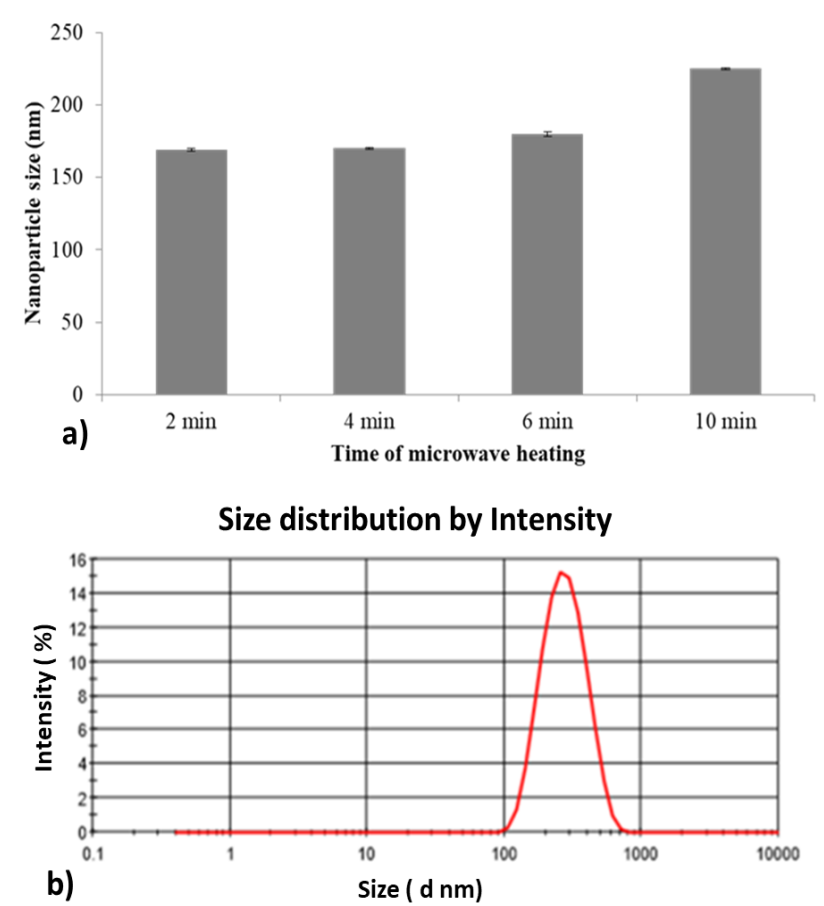

Figure 1. a) Aggregates $\mathrm{ZnO}$ nanoparticles hydrodynamic size at different irradiation time of microwave heating (watt) based on DLS analysis. b) Size distribution by intensity of aggregates $\mathrm{ZnO}$ nanoparticles synthesized at $2 \mathrm{~min}$ of microwave irradiation time utes, 4 minutes, 6 minutes and 10 minutes. The white precipitate was cleaned using distilled water before the precipitate was dried in an oven at $80^{\circ} \mathrm{C}$.

\subsection{Characterization}

$30 \mu \mathrm{L}$ of $\mathrm{ZnO}$ solution was diluted in $2 \mathrm{~mL}$ of de-ionized water. The nanoparticle sizes based on DLS analysis were measured using Zetasizer Nano ZS (Malvern Instruments). The optical properties of $\mathrm{ZnO}$ nanoparticles was analysed using the UV-vis spectrophotometer in the range of $250 \mathrm{~nm}$ to $800 \mathrm{~nm}$. The chemical composition of the synthesized nanoparticles was studied using the by a Shimadzu Fourier Transform Infrared (FTIR) spectrophotometer in the range of $400-4000 \mathrm{~cm}^{-1}$. The crystal structures of the prepared $\mathrm{ZnO}$ nanoparticles were analyzed using the Philips X'Pert MPD (Multi-Purpose Diffractometer) $\mathrm{XRD}$ using $\mathrm{Cu}-\mathrm{K} \alpha 1$ radiation $(\lambda=1.5406 \mathrm{~nm})$. The X-ray powder diffraction patterns were recorded at every $0.01^{\circ}$ in the angular range of $20^{\circ}-80^{\circ}$ using monochromatic X-rays. The size and the morphology of the $\mathrm{ZnO}$ nanoparticle were examined using the field emission scanning electron microscope (FESEM). The $\mathrm{ZnO}$ nanoparticles were disperse in ethanol and sonicated for 15 minutes. Next the disperse solution of $\mathrm{ZnO}$ nanoparticles were dried on the carbon tape. The sample was coated with platinum in order to avoid charging during the observation.

\section{Results and Discussion}

DLS is a characterization technique which is commonly used for calculating the hydrodynamic diameters of suspended nanoparticles based on their Brownian movements [23]. DLS produces absolute values for an ensemble of particles. As shown in Figure 1(a), the calculated average hydrodynamic diameter based on DLS analysis shows aggregates $\mathrm{ZnO}$ nanoparticles size that are approximately similar value which are $168 \mathrm{~nm}, 170 \mathrm{~nm}$, and $180 \mathrm{~nm}$ at 2 minutes, 4 minutes and 6 minutes respectively. The slight increase in the aggregates nanopar-

Table 2. Average crystallite size of $\mathrm{ZnO}$ nanoparticles synthesis 2 minutes of microwave irradiation obtained from (101) plane

\begin{tabular}{cccccc}
\hline $2 \theta$ & FHWM & $\begin{array}{c}\text { Average crys- } \\
\text { tallite size (D) } \\
(\mathrm{nm})\end{array}$ & $\begin{array}{c}\text { Inter planner } \\
\text { distance }(\mathrm{d}) \\
(\mathrm{nm})\end{array}$ & $\begin{array}{c}\text { Cell } \\
\text { parameter } \\
a=b\end{array}$ & \multicolumn{2}{c}{ Cell } \\
parameter \\
$c$
\end{tabular}


ticles size within 6 minutes of microwave irradiation might be cause of the protective role of gum arabic, as it retards the growth and agglomeration of nanoparticles by steric effect [16].

At 10 minutes of microwave irradiation time, the aggregates nanoparticles size increased to $225 \mathrm{~nm}$ almost $34 \%$ from the size at 2 minutes of microwave irradiation time. It was found that by increasing irradiation time to 10 minutes, the aggregates nanoparticle size of $\mathrm{ZnO}$ nanoparticles increased. This was mainly due to the fact that both processes of nucleation as well as crystal growth were affected by microwave irradiation time which indirectly promoted the larger particles. In addition, longer microwave irradiation times will directly increase the heating rate that will effected the gum arabic coating to stabilized the resulted nanoparticle increase in the aggregates nanoparticles size.

This result is similar with other report finding that by increasing microwave irradiation time from 10 to 15 minutes, aggregates $\mathrm{ZnO}$ nanoparticles size increased from 50 to 150 [24]. Due to its penetration characteristics, microwave irradiation can speed up the reaction rate homogeneously resulted uniform nuclea-

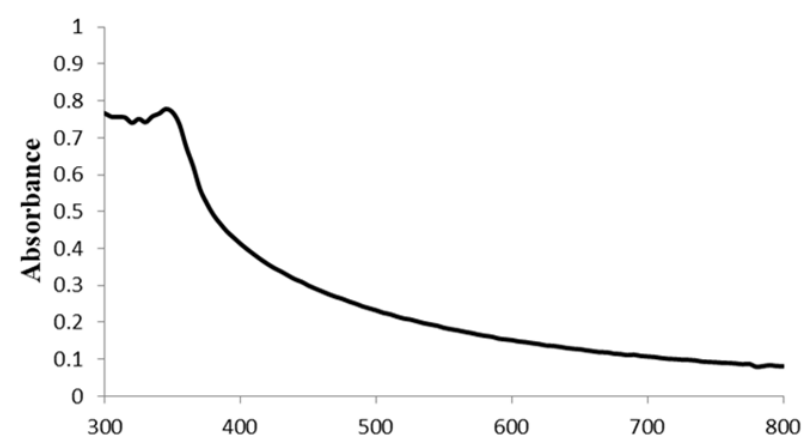

a) Wavelength

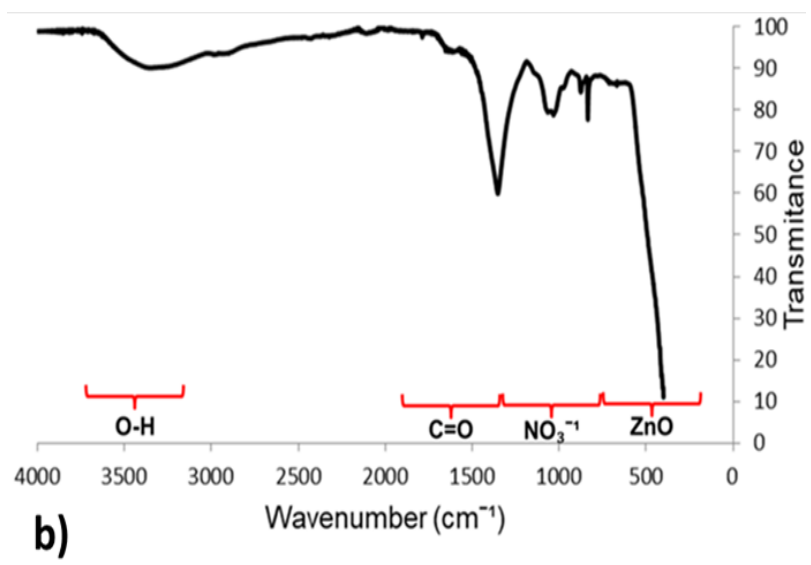

tion and quick crystal growth for development of crystallites with narrow size distribution [25]. As shown in Figure 1(b), besides small particle size, microwave assisted synthesis resulted a unimodal narrow particle size distribution of $\mathrm{ZnO}$ nanoparticles. A unimodal narrow particle size distribution directly demonstrated monodisperse condition of the $\mathrm{ZnO}$ nanoparticles solution. The polydispersity index (PDI) of this $\mathrm{ZnO}$ nanoparticle synthesis at 2 min of microwave irradiation time was 0.101 as shown in Table 1 . A sample with PD $<20 \%$ are considered to be monodisperse [26]. As the aim to obtain the smaller size of $\mathrm{ZnO}$ nanoparticle, microwave irradiation time at 2 minutes was selected as the best microwave irradiation time for $\mathrm{ZnO}$ nanoparticles synthesis. Figure 2(a) shows the optical properties of $\mathrm{ZnO}$ nanoparticles synthesized at 2 minutes of irradiation time. A sharp peak was formed at 355 $\mathrm{nm}$, representing the hexagonal phase of $\mathrm{ZnO}$ nanoparticle [27].

In order to understand the mechanism of the formation of $\mathrm{ZnO}$ nanoparticles, the FTIR measurement was conducted at room temperature for wavenumber ranging from $4000 \mathrm{~cm}^{-1}$ to $400 \mathrm{~cm}^{-1}$. Figure 2(b) shows the compositional analysis of $\mathrm{ZnO}$ nanoparticles synthesized at 350 watt. The broad band at $3447 \mathrm{~cm}^{-1}$ corresponded to the $\mathrm{O}-\mathrm{H}$ mode of vibration within the hydroxyl groups. A peak at 1352 $\mathrm{cm}^{-1}$ might be due to carboxylic acid. A peak near 1033-835 $\mathrm{cm}^{-1}$ is due to $\mathrm{NO}_{3}$ bonding which might be due to the absorption of nitric acid group on the $\mathrm{ZnO}$ surface. The peak in the region between 424 to $475 \mathrm{~cm}^{-1}$ is allotted to $\mathrm{Zn}-\mathrm{O}$ stretching [28].

XRD diffraction patterns of the $\mathrm{ZnO}$ nanoparticles synthesized at 2 minutes of irradiation time is shown in Figure 2(c). There are

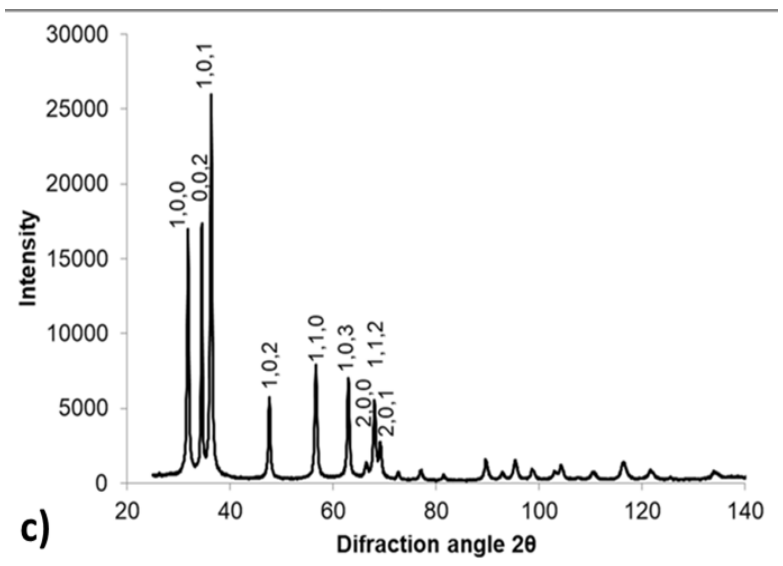

Figure 2. a) UV-vis spectra of $\mathrm{ZnO}$ nanoparticles b) FTIR spectra of $\mathrm{ZnO}$ nanoparticles c) XRD spectra of $\mathrm{ZnO}$ nanoparticles synthesized at 2 min of microwave irradiation time 
nine diffraction peaks position at $2 \theta$ of 31.8 , $34.4,36.2,47.5,56.6,62.8,66.4,67.9$, and 69.1 which corresponded to the (100), (002), (101), (102), (110), (103), (200), (112), and (201) crystal planes of hexagonal wurtzite $\mathrm{ZnO}$, respectively [29].

X'Pert High Score version 2.0 was used to measure the $\mathrm{x}$-ray wavelength, the full width at half-maximum (FWHM) of the diffraction line and the diffraction angle. On the other hand, the crystallite size was calculated using the Scherrer equation Equation (1) for the broadening of diffraction peaks [30].

$$
L C=\frac{180}{\pi} \cdot \frac{K \cdot \lambda}{\cos \theta \sqrt{F W H M^{2}-s^{2}}}
$$

Here, $K$ is the wavelength of $\mathrm{Cu}(1.5406 \AA)$, s is the instrumental broadening (0), $\lambda$ is the Scherrer constant (0.89), FWHM is the fullwidth at half-maximum of the (101) plane attained from the EVA software, and $\theta$ is the angle of (101) plane. Table 2 shows the calculated average crystallite size of $\mathrm{ZnO}$ nanoparticles synthesis in 2 minutes of irradiation time was $25 \mathrm{~nm}$.

FESEM image as shown in Figure 3 showed spherical morphology controlled growth of aggregates $\mathrm{ZnO}$ nanoparticles at 2 minutes of microwave irradiation time. Despite size increasing, microwave irradiation time not result in a significant morphological change when microwave irradiation time exceeds 10 minutes (Figure not included). This may be due to the

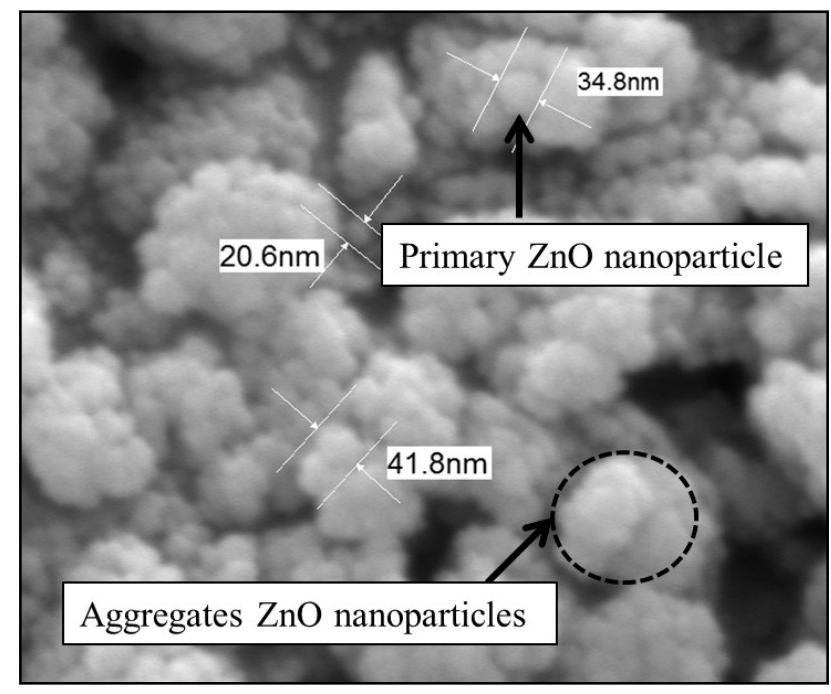

Figure 3. FESEM image of aggregates $\mathrm{ZnO}$ nanoparticles at $2 \mathrm{~min}$ of microwave irradiation time. The primary size of $\mathrm{ZnO}$ nanoparticle was calculated $20-40 \mathrm{~nm}$, and the aggregates size was 150-200 nm steric effect of gum arabic as stabilizing and capping agent that control the polarization of $\left[\mathrm{Zn}(\mathrm{OH})_{4}\right]^{2-}$ as growth species. Some researchers reported incompatible result, which is the morphology of $\mathrm{ZnO}$ nanoparticles change with irradiation time forming including $\mathrm{ZnO}$ starshaped, needle-shaped, and flower-shaped $[13,19]$.

\section{Conclusions}

Microwave-assisted heating is a low cost, simple and greener approach to synthesize $\mathrm{ZnO}$ nanoparticles by using gum arabic as stabilizing agent. In this study, size and morphology-controlled growth of $\mathrm{ZnO}$ nanoparticles was achieved within range of investigated microwave irradiation time. $\mathrm{ZnO}$ nanoparticles size increase with the increase of microwave irradiation time. Two minutes of microwave irradiation time is sufficient in order to obtain small size of $\mathrm{ZnO}$ nanoparticles at 350 watt.

\section{Acknowledgment}

We acknowledge the financial support from a research university Grant number RDU 150333 of University Malaysia Pahang (UMP) and Mybrain15 scholarship under Ministry of Higher Education Malaysia. Thanks for providing all facilities to carry out this research work and for awarding financial support through Doctoral Scholarship Scheme.

\section{References}

[1] Naveed Ul Haq, A., Nadhman, A., Ullah, I., Mustafa, G., Yasinzai, M., Khan, I. (2017). Synthesis Approaches of Zinc Oxide Nanoparticles: The Dilemma of Ecotoxicity. J. Nanomater., 2017: 1-14 (Article ID 8510342)

[2] Sathya, M., Pushpanathan, K. (2018). Synthesis and Optical Properties of $\mathrm{Pb}$ Doped ZnO Nanoparticles. Appl. Surf. Sci., 449: 346-357.

[3] Ouhaibi, A., Ghamnia, M., Dahamni, M.A., Heresanu, V., Fauquet, C., Tonneau, D. (2018). The Effect of Strontium Doping on Structural and Morphological Properties of $\mathrm{ZnO}$ Nanofilms Synthesized by Ultrasonic Spray Pyrolysis Method. J. Sci. Adv. Mater. Devices, 3: 29-36.

[4] Kumaresan, N., Ramamurthi, K., Ramesh Babu, R., Sethuraman, K., Moorthy Babu, S. (2017). Hydrothermally Grown ZnO Nanoparticles for Effective Photocatalytic Activity. Appl. Surf. Sci., 418: 138-146.

[5] Irshad, K., Khan, M.T., Murtaza, A. (2018). Synthesis and Characterization of Transition- 
Metals-Doped ZnO Nanoparticles by Sol-Gel Auto-Combustion Method. Phys. B Condens. Matter, 543: 1-6.

[6] Unalan, H.E., Hiralal, P., Rupesinghe, N., Dalal, S., Milne, W.I., Amaratunga, G.A.J. (2008). Rapid Synthesis of Aligned Zinc Oxide Nanowires. Nanotechnology, 19(25): 56085612

[7] Gray, R.J., Jaafar, A.H., Verrelli, E., Kemp, N.T. (2018). Method to Reduce the Formation of Crystallites in $\mathrm{ZnO}$ Nanorod Thin-Films Grown via Ultra-Fast Microwave Heating. Thin Solid Films, 662: 116-122.

[8] Abdelkader, R., Mohammed, B. (2016). Green Synthesis of Cationic Polyacrylamide Composite Catalyzed by An Ecologically Catalyst Clay Called Maghnite- $\mathrm{H}^{+}$(Algerian MMT) Under Microwave Irradiation. Bull. Chem. React. Eng. Catal., 11(2): 170-175.

[9] Pauzi, N., Zain, N.M., Yusof, N.A.A. (2018). The Potential of Gallic Acid and Ascorbic Acid as Green Reducing Agent in ZnO Nanoparticle Synthesis. Malaysian J. Catal., 3: 13-16.

[10] Wojnarowicz, J., Chudoba, T., Gierlotka, S., Lojkowski, W. (2018). Effect of Microwave Radiation Power on the Size of Aggregates of $\mathrm{ZnO}$ NPs Prepared Using Microwave Solvothermal Synthesis. Nanomaterials, 8(5): 343-359

[11] Gaba, M., Dhingra, N. (2011). Microwave Chemistry: General Features and Applications. Indian J. Pharm. Educ. Res., 45: 175183.

[12] Breitwieser, D., Moghaddam, M.M., Spirk, S., Baghbanzadeh, M., Pivec, T., Fasl, H., Ribitsch, V., Kappe, C.O. (2013). In Situ Preparation of Silver Nanocomposites on Cellulosic Fibers-Microwave vs. Conventional Heating. Carbohydr. Polym., 94: 677-686.

[13] Motshekga, S.C., Pillai, S.K., Sinha Ray, S., Jalama, K., Krause, R.W.M. (2012). Recent Trends in the Microwave-Assisted Synthesis of Metal Oxide Nanoparticles Supported on Carbon Nanotubes and Their Applications. J. Nanomater., 2012: 1-15. (Article ID 691503)

[14] Renard, D., Garnier, C., Lapp, A., Schmitt, C., Sanchez, C. (2012). Structure of Arabinogalactan-Protein from Acacia Gum: From Porous Ellipsoids to Supramolecular Architectures. Carbohydr. Polym., 90: 322-332.

[15] Sabyasachi Maiti, Sougata Jana, B.L. (2018). Cationic Polyelectrolyte-biopolymer Complex Hydrogel Particles for Drug Delivery. Des. Dev. New Nanocarriers, 223-256.

[16] Barik, P., Bhattacharjee, A., Roy, M. (2015). Preparation, Characterization and Electrical Study of Gum Arabic / ZnO Nanocomposites. Bull. Mater. Sci., 38: 1609-1616.
[17] Cho, S., Jung, S.-H., Lee, K.-H. (2008). Morphology-Controlled Growth of $\mathrm{ZnO}$ Nanostructures Using Microwave Irradiation: From Basic to Complex Structures. J. Phys. Chem. C, 112: 12769-12776.

[18] Barreto, G.P., Morales, G., Quintanilla, M.L.L. (2013). Microwave Assisted Synthesis of $\mathrm{ZnO}$ Nanoparticles : Effect of Precursor Reagents, Temperature, Irradiation Time, and Additives on Nano-ZnO Morphology Development. J. Mater., 2013: 1-12.

[19] Sulochana, M., Vani, C.S., Devi, D.K., Naidu, N.V.S., Sreedhar, B. (2013). Synthesis and Characterization of Gum Acacia-Stabilized Zinc Oxide Nanoparticles: A Green Approach and Microbial Activity. Am. J. Mater. Sci., 3: 169-177.

[20] Liu, M.H., Tseng, Y.H., Greer, H.F., Zhou, W., Mou, C.Y. (2012). Dipole Field Guided Orientated Attachment of Nanocrystals to TwinBrush ZnO Mesocrystals. Chem. - A Eur. J., 18: 16104-16113.

[21] Bhattacharjee, S. (2016). DLS and Zeta Potential - What They Are and What They Are Not? J. Control. Release, 235: 337-351.

[22] Chirikov, S.N. (2016). Comparison of Particle Size Measurements of Some Aqueous Suspensions by Laser Polarimetry and Dynamic Light Scattering. J. Phys. Conf. Ser., 747: 012051

[23] Brar, S.K., Verma, M. (2011). Measurement of Nanoparticles by Light-Scattering Techniques. TrAC - Trends Anal. Chem., 30: 4-17.

[24] Hasanpoor, M., Aliofkhazraei, M., Delavari, H. (2015). Microwave-Assisted Synthesis of Zinc Oxide Nanoparticles. Procedia Mater. Sci., 11: 320-325.

[25] Kazemzadeh, S.M., Vaezi, M.R., Shokuhfar, A. (2011). The Effect of Microwave Irradiation Time on Appearance Properties of Silver Nanoparticles. Trans. Indian Inst. Met., 64: 261-264.

[26] Arzenšek, D., Podgornik, R., Kuzman, D. (2010). Dynamic Light Scattering and Application to Proteins in Solutions. In Seminar; University of Ljubljana: Ljubljana, Slovenia, $1-18$

[27] Papadaki, D., Foteinis, S., Mhlongo, G.H., Nkosi, S.S., Motaung, D.E., Ray, S.S., Tsoutsos, T., Kiriakidis, G. (2017). Life Cycle Assessment of Facile Microwave-Assisted Zinc Oxide (ZnO) Nanostructures. Sci. Total Environ., 586: 566-575.

[28] Manoj, V., Karthika, M., Praveen Kumar, V.S.R., Boomadevi, S., Jeyadheepan, K., Karn, R.K., Balaguru, R.J.B., Pandiyan, S.K. (2014). Synthesis of ZnO Nanoparticles Using Carboxymethyl Cellulose Hydrogel. Asian J. Appl. Sci., 7: 798-803. 
[29] Kumar, R., Singh, R.K., Singh, D.P., Savu, R., Moshkalev, S.A. (2016). Microwave Heating Time Dependent Synthesis of Various Dimensional Graphene Oxide Supported Hierarchical $\mathrm{ZnO}$ Nanostructures and Its Photoluminescence Studies. Mater. Des., 111: 291-300.

[30] Alias, S.S., Ismail, A.B., Mohamad, A.A. (2010). Effect of $\mathrm{pH}$ on $\mathrm{ZnO}$ Nanoparticle Properties Synthesized by Sol-Gel Centrifugation. J. Alloys Compd., 499: 231-237.
[31] Barreto, G., Morales, G., Cañizo, A., Eyler, N. (2015). Microwave Assisted Synthesis of $\mathrm{ZnO}$ Tridimensional Nanostructures. Procedia Mater. Sci., 8: 535-540.

Selected and Revised Papers from The $4^{\text {th }}$ International Conference of Chemical Engineering \& Industrial Biotechnology (ICCEIB 2018) (http://icceib.ump.edu.my/index.php/en/) (Universiti Malaysia Pahang, by 1 15t-2nd August 2018) after Peer-reviewed by Scientific Committee of ICCEIB 2018 and Peer-Reviewers of Bulletin of Chemical Reaction Engineering \& Catalysis 